\title{
Sneddon-Wilkinson disease treated with etanercept: report of two
}

\section{cases}

\author{
D. R. Berk, M. A. Hurt, * C. Mann and D. Sheinbein
}

Department of Internal Medicine, Division of Dermatology, Washington University School of Medicine, St Louis, MO, USA; and *Cutaneous Pathology, WCP Laboratories Inc., Maryland Heights, MO, USA

doi:10.1111/j.1365-2230.2008.02905.x

\section{Summary}

Sneddon-Wilkinson disease (SWD), also known as subcorneal pustular dermatosis, is a rare, chronic eruption that is often difficult to treat, particularly in patients who do not respond to or cannot tolerate dapsone. Few case reports exist of patients with SWD treated with antitumour necrosis factor- $\alpha$ therapy. We report two patients with SWD refractory to numerous treatments, who responded to etanercept (in combination with low-dose acitretin in one case).

Sneddon-Wilkinson disease (SWD), also known as subcorneal pustular dermatosis, is a rare, chronic eruption characterized by annular, superficial, sterile pustules typically involving the intertriginous areas, trunk and proximal limbs. ${ }^{1}$ SWD often affects middleaged women, may be associated with autoimmune disorders and is often difficult to treat. ${ }^{1}$ To our knowledge, there are three case reports of antitumour necrosis factor- $\alpha$ (TNF- $\alpha$ ) therapy with infliximab for SWD ${ }^{2-4}$ and two case reports of etanercept for SWD. ${ }^{5,6}$ We report two patients whose SWD was refractory to numerous treatments before responding to etanercept $50 \mathrm{mg}$ twice weekly (in combination with low-dose acitretin in one case).

\section{Report}

Patient 1 was a 51-year-old white man who presented with a 3-year history of a pruritic, pustular rash affecting the trunk, groin and limbs. The referring dermatologist had diagnosed subcorneal pustular dermatosis but the condition had been refractory to topical corticosteroids and acitretin $25 \mathrm{mg}$ twice daily.

Correspondence: Dr David R. Berk, Washington University School of Medicine, Division of Dermatology, 660 S. Euclid, Campus Box 8123, St Louis, MO 63110, USA

E-mail: dberk@im.wustl.edu

Conflict of interest: none declared

Accepted for publication 16 March 2008
Physical examination revealed scaly, erythematous pustules, papules and plaques on the trunk, groin and proximal limbs covering $20 \%$ body surface area (BSA) (Fig. 1a). Potassium hydroxide examination and fungal and bacterial cultures were negative. A punch biopsy was taken, and histological examination revealed a well-defined, sterile, subcorneal pustule with a superficial perivascular inflammatory infiltrate of lymphocytes and neutrophils and negative direct immunofluorescence, consistent with SWD (Fig. 1b-d).

Over the next 3 years, multiple treatments were attempted without benefit, including topical corticosteroids, pimecrolimus and tazarotene, narrowband ultraviolet (UV)B and oral cefdinir, tetracycline, dapsone, colchicine and methotrexate. No paraproteinaemia was found with serum protein electrophoresis. Etanercept $50 \mathrm{mg}$ twice weekly was started as monotherapy. Three months later, the SWD was significantly improved $(<5 \%$ BSA). Eight months after starting etanercept, his SWD flared, involving 7\% BSA. Acitretin was prescribed at a dose of $25 \mathrm{mg}$ every other day. One month later, the SWD had nearly cleared and the patient was only taking $25 \mathrm{mg}$ of acitretin twice weekly in addition to etanercept. The patient's SWD was virtually clear at last follow-up 13 months later (22 months after starting etanercept, maintained at $50 \mathrm{mg}$ twice weekly).

Patient 2 was a 61-year-old African American man with a history of hypertension and coronary artery disease, who was referred with a history of several 

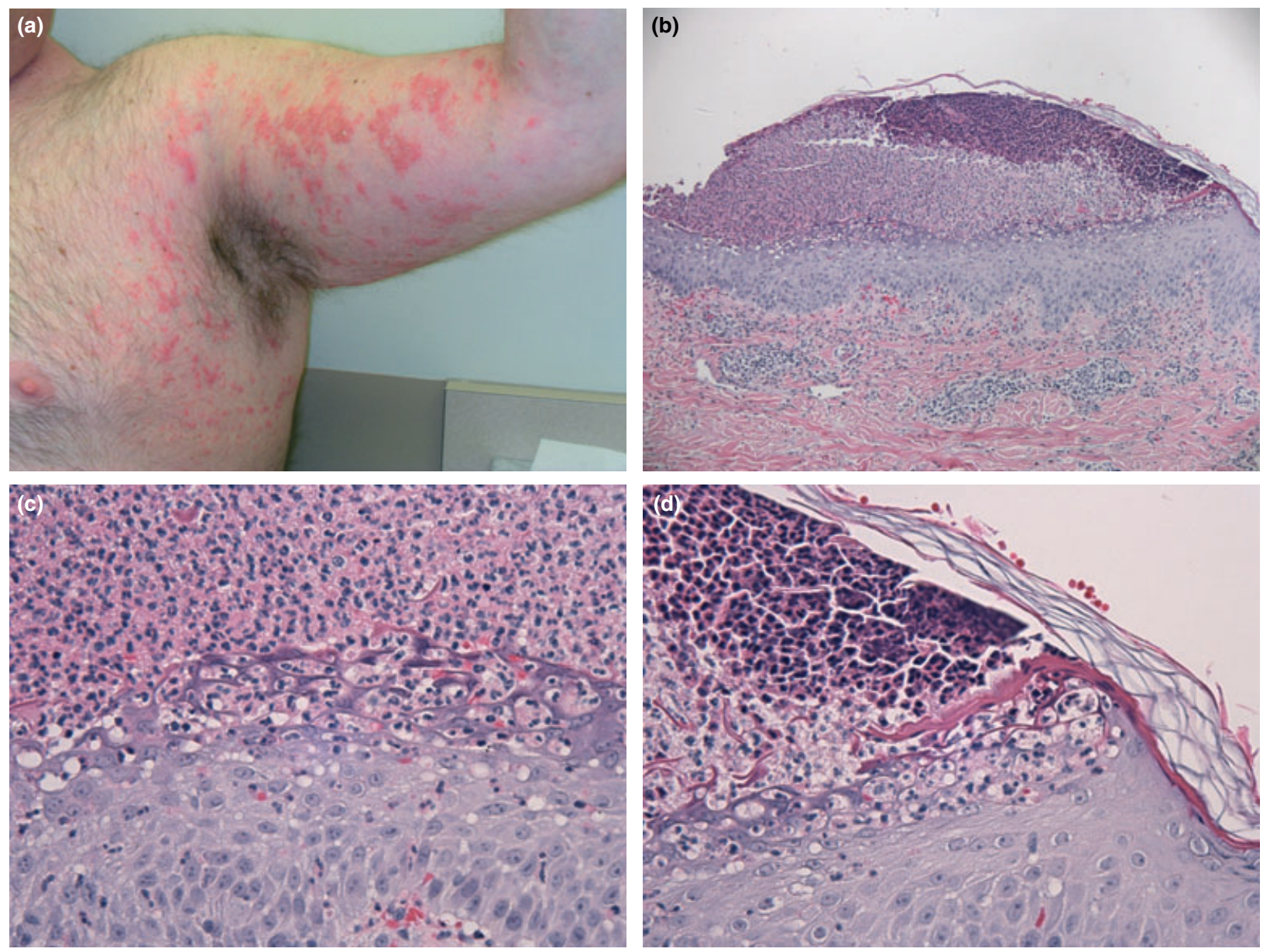

Figure 1 Patient 1, before etanercept, (a) Scaly, erythematous pustules, papules and plaques on the right arm and chest; (b) Biopsy taken from the chest shows a subcorneal pustule with spongiform areas in the superficial epidermis; (c) accumulation of neutrophils present below the cornified layer and within smaller cavities in the superficial epidermis; (d) sharp demarcation of the subcorneal/intraepidermal pustule. Haematoxylin and eosin (b) $\times 10$; (c, d) $\times 40$.

months of pruritic, erythematous and crusted papules and pustules on the chest, upper back and proximal thighs (approximately 10\% BSA) (Fig. 2a).

Biopsies taken by the referring dermatologist had shown intracorneal pustules with slight dermal inflammation with neutrophils and negative direct immunofluorescence, consistent with SWD (Fig. 2b-d). Multiple bacterial cultures were negative.

Over the next 3 years, multiple medications were attempted without benefit, including psoralen UVA, topical steroids, mupirocin, ketoconzole, salicylic acid and hydroquinone and tretinoin (for postinflammatory hyperpigmentation) and oral dapsone, colchicine, mycophenolate mofetil, antihistamines and short-courses of prednisone. No paraproteinaemia was detected on quantitative immunoglobulin measurements.

Etanercept $50 \mathrm{mg}$ twice weekly was started as systemic monotherapy, with topical steroids as needed. At follow-up 1 and 4 months after starting treatment, he was markedly improved. At the 7-month follow-up, the SWD was slightly flaring but remained wellcontrolled with $<5 \%$ BSA involvement, and at the 9-month follow-up, it was markedly improved (Fig. 2e). The patient noted that his SWD was better controlled on

Figure 2 Patient 2. Before etanercept, (a) erythematous papules and pustules and postinflammatory pigmentary changes on the back; (b) biopsy taken from the right upper back shows subcorneal pustule with minimal involvement of the epidermis and (c) accumulations of neutrophils below the cornified layer and within smaller cavities in the superficial epidermis; (d) biopsy taken from the right lower back shows neutrophils located focally below the cornified layer and in the superficial epidermis. Haematoxylin and eosin (b) $\times 10$; (c) $\times 40$; (d) $\times 20$. (e) Marked improvement 9 months after starting etanercept. 

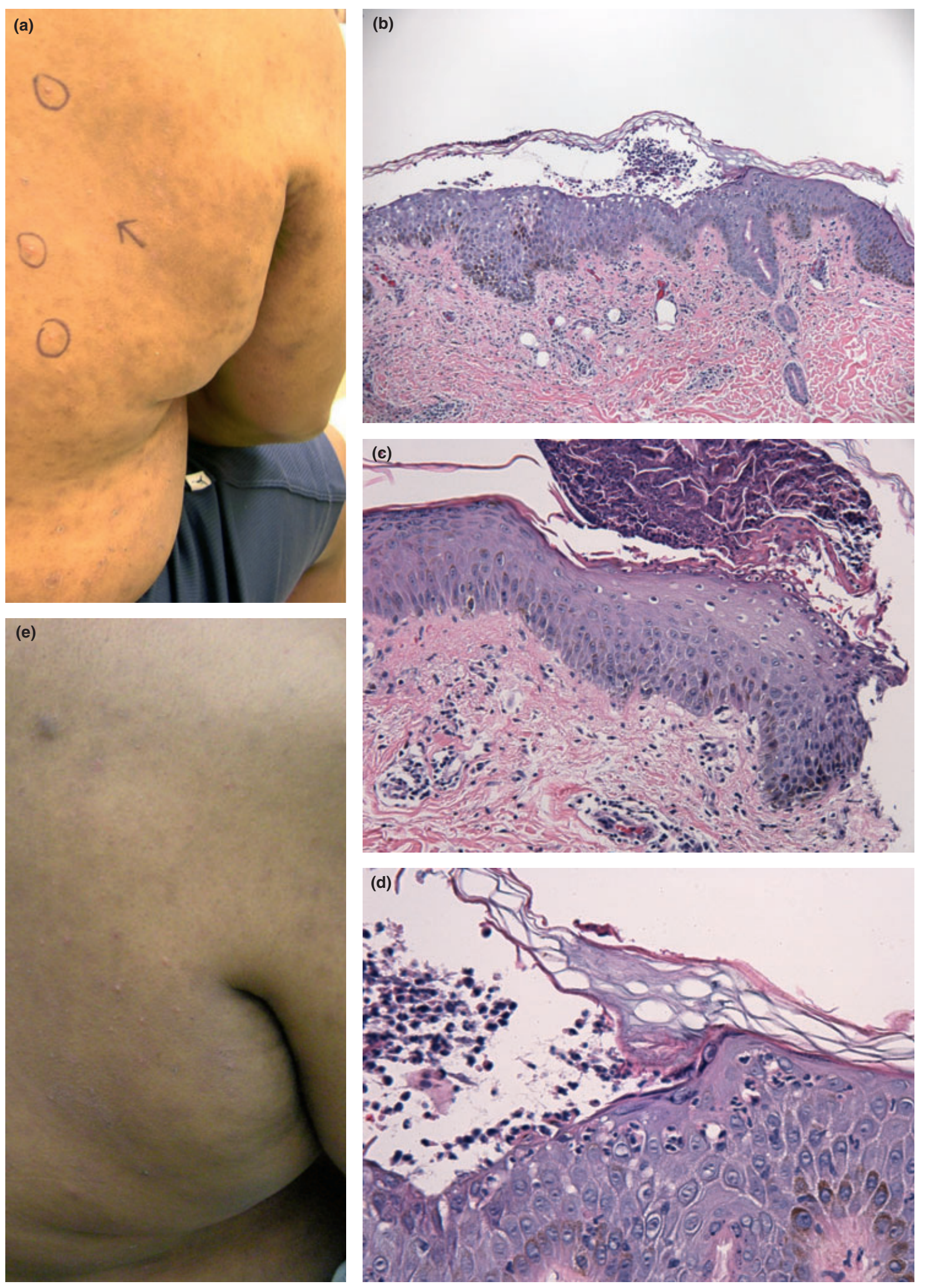
Sneddon-Wilkinson disease treated with etanercept $\bullet$ D. R. Berk et al.

Table 1 Summary of cases of Sneddon-Wilkinson disease treated with anti-tumour necrosis factor agents.

\begin{tabular}{|c|c|c|c|c|}
\hline Reference & Patient details & Previous treatment & Response & Follow-up \\
\hline Voigtlander et al. & $\begin{array}{l}\text { 79-year-old } \\
\text { white woman }\end{array}$ & $\begin{array}{l}\text { Colchicine, retinoids, corticosteroids, } \\
\text { phototherapy, azathioprine, } \\
\text { azulfidine, acitretin, dapsone }\end{array}$ & $\begin{array}{l}\text { Responded to two } \\
\text { infusions of infliximab }\end{array}$ & $\begin{array}{l}\text { Maintained on } \\
\text { methylprednisone and } \\
\text { acitretin } \times 3 \text { months, } \\
\text { then acitetrin } \\
\text { monotherapy } \times 6 \text { months }\end{array}$ \\
\hline Bonifati et al. & $\begin{array}{l}\text { 54-year-old } \\
\text { white woman }\end{array}$ & $\begin{array}{l}\text { Corticosteroids, retinoids, ciclosporin, } \\
\text { colchicine, PUVA, dapsone }\end{array}$ & $\begin{array}{l}\text { Responded to first but } \\
\text { not second infliximab } \\
\text { infusion }\end{array}$ & $\begin{array}{l}\text { First infusion led to } \\
\text { improvement } \times 3 \text { months }\end{array}$ \\
\hline Raimondo et al. & $\begin{array}{l}\text { 61-year-old } \\
\text { white woman }\end{array}$ & $\begin{array}{l}\text { Dapsone, azathioprine, ciclosporin, } \\
\text { retinoids, corticosteroids }\end{array}$ & $\begin{array}{l}\text { Responded to single } \\
\text { infliximab infusion but } \\
\text { relapsed } 15 \text { days later }\end{array}$ & $\begin{array}{l}\text { Subsequently responded to } \\
\text { efalizumab }\end{array}$ \\
\hline lobst and Ingraham & $\begin{array}{l}\text { 27-year-old } \\
\text { white woman }\end{array}$ & Dapsone & Cleared with etanercept & Not reported \\
\hline Bedi & $\begin{array}{l}\text { 28-year-old } \\
\text { white woman }\end{array}$ & $\begin{array}{l}\text { Topical corticosteroids, calcipotriol, } \\
\text { dapsone and tacrolimus, and oral } \\
\text { tetracycline, colchicine, nicotinamide, } \\
\text { potassium iodide and dapsone }\end{array}$ & $\begin{array}{l}\text { Responded to etanercept } \\
25 \mathrm{mg} \text { twice weekly } \\
\text { and nearly cleared at } \\
50 \mathrm{mg} \text { twice weekly }\end{array}$ & $\begin{array}{l}11 \text { months of follow-up on } \\
\text { etanercept }\end{array}$ \\
\hline \multicolumn{5}{|l|}{ Current study } \\
\hline Case 1 & $\begin{array}{l}\text { 54-year-old } \\
\text { white man }\end{array}$ & $\begin{array}{l}\text { Topical corticosteroids, pimecrolimus, } \\
\text { and tazarotene, NB-UVB, and oral } \\
\text { cefdinir, tetracycline, dapsone, } \\
\text { colchicine and methotrexate }\end{array}$ & $\begin{array}{l}\text { Responded to etanercept } \\
50 \text { mg twice weekly as } \\
\text { monotherapy } \times 8 \text { months, } \\
\text { flared, now nearly clear } \\
\text { with addition of acitretin } \\
25 \text { mg twice weekly } \times \\
14 \text { months }\end{array}$ & 22 months of follow-up in total \\
\hline Case 2 & $\begin{array}{r}64 \text {-year-old } \\
\text { black man }\end{array}$ & $\begin{array}{l}\text { PUVA, topical steroids, mupirocin, } \\
\text { ketoconazole, salicylic acid, } \\
\text { hydroquinone and tretinoin, and } \\
\text { oral dapsone, colchicine, } \\
\text { mycophenolate mofetil, } \\
\text { antihistamines and prednisone }\end{array}$ & $\begin{array}{l}\text { Responded to etanercept } \\
50 \mathrm{mg} \text { twice weekly }\end{array}$ & 7 months of follow-up in total \\
\hline
\end{tabular}

NB-UVB, narrowband ultraviolet B; PUVA, psoralen ultraviolet A.

etanercept (maintained at $50 \mathrm{mg}$ twice weekly) than any previous treatment.

Many treatments for SWD have been reported, including dapsone, sulfapyridine, corticosteroids, retinoids, colchicine, ketoconazole, minocycline, ciclosporin, mebhydroline and phototherapy. ${ }^{1}$ Although dapsone is often considered to be the first-line treatment, some patients fail to respond or cannot tolerate the sideeffects including haemolytic anaemia. In terms of antitumour necrosis factor (TNF)- $\alpha$ treatments, we are aware of only three reports of infliximab $b^{2-4}$ and two reports of etanercept for SWD (Table 1).,

The role of TNF- $\alpha$ in the pathogenesis of SWD is also supported by a case report ${ }^{7}$ that showed increases in blister fluid and serum TNF- $\alpha$ levels in SWD. Furthermore, TNF- $\alpha$ plays an important role in the pathogenesis of inflammatory bowel diseases, pyoderma gangrenosum and rheumatoid arthritis, which have all been associated with SWD. Finally, some authors believe that SWD may evolve into or even be a variant of pustular psoriasis, consistent with a therapeutic role for anti-TNF- $\alpha$ treatments. ${ }^{8,9}$

Although combination therapy was used for patient 1 , the patient had previously showed improvement with etanercept monotherapy for 8 months and has only required a minimal addition of acitretin $(25 \mathrm{mg}$ twice weekly) for the past 14 months. Our cases show that anti-TNF- $\alpha$ agents may be useful in treating SWD, in combination with other agents or possibly as monotherapy, particularly in patients who are unable to tolerate or are refractory to dapsone.

\section{References}

1 Lutz ME, Daoud MS, McEvoy MT, Gibson LE. Subcorneal pustular dermatosis: a clinical study of ten patients. Cutis 1998; 61: 203-8.

2 Voigtlander C, Luftl M, Schuler G, Hertl M. Infliximab (antitumor necrosis factor alpha antibody): a novel, highly effective treatment of recalcitrant subcorneal pustular 
dermatosis (Sneddon-Wilkinson disease). Arch Dermatol 2001; 137: 1571-4.

3 Bonifati C, Trento E, Cordiali Fei P et al. Early but not lasting improvement of recalcitrant subcorneal pustular dermatosis (Sneddon-Wilkinson disease) after infliximab therapy: relationships with variations in cytokine levels in suction blister fluids. Clin Exp Dermatol 2005; 30: 662-5.

4 Raimondo N, Campos de Gonzalez L, Orden A. SneddonWilkinson's syndrome: a therapeutic challenge. Poster abstract presented at the American Academy of Dermatology 65th Annual Meeting. J Am Acad Dermatol 2007; 56 (Suppl. 2): AB46.

5 Iobst W, Ingraham K. Sneddon-Wilkinson disease in a patient with rheumatoid arthritis. Arthritis Rheum 2005; 52: 3771 .
6 Bedi MK. Successful treatment of longstanding, recalcitrant subcorneal pustular dermatosis with etanercept. Skinmed 2007; 6: 245-7.

7 Grob JJ, Mege JL, Capo C et al. Role of tumor necrosis factor-alpha in Sneddon-Wilkinson subcorneal pustular dermatosis. A model of neutrophil priming in vivo. $\mathrm{J} \mathrm{Am}$ Acad Dermatol 1991; 25: 944-7.

8 Sanchez NP, Perry HO, Muller SA, Winkelmann RK. Subcorneal pustular dermatosis and pustular psoriasis. A clinicopathologic correlation. Arch Dermatol 1983; 119: 715-21.

9 Reed J, Wilkinson J. Subcorneal pustular dermatosis. Clin Dermatol 2000; 18: 301-13. 